\title{
Investigation of the Track Gauge in Straight Sections, Considering Hungarian Railway Lines
}

\section{Dalma Németh, Henriett Horváth, Majid Rad Movahedi, Attila Németh, Szabolcs Fischer}

Széchenyi István University

Egyetem tér 1, H-9026, Győr, Hungary

nemeth.dalma@hallgato.sze.hu,

\{horvath.henriett,majidmr,nemeth.attila,fischersz\}@sze.hu

\begin{abstract}
In this work, considering the MÁV's (i.e., the Hungarian Railways) five small and five high-traffic railway lines, the statistical distribution and change of the track gauge parameter were analyzed, under a ten year, on time-series analysis, related to straight track sections. The analysed data, were bottom track gauge measurements, of the FMK-004 and FMK-007 type railway track geometry, measuring and recording car \& wagon. Taking into account the railway tracks, the track gauge parameter cannot be controlled and improved upon by large machine methods, but its permitted value depends on the allowed speed (and vice versa). The main independent variables were the elapsed time and the through-rolled axle tons (as a function of time, i.e., the MGT). To generate the statistical analyses, Vaszarylike shape numbers were computed, considering the distribution functions of the measured data series of the track gauge parameter every $25 \mathrm{~cm}$. The authors examined the change of the shape numbers, the average and standard deviation values of the track gauge, and the shape of the distribution functions (skewness and kurtosis properties). In the end, a spectrum analysis of the measured data series was produced. In conclusion, the Authors provide relevant statements regarding the track gauge parameter.
\end{abstract}

Keywords: railway track; track gauge; statistical analysis; time-series analysis; distribution

\section{Introduction}

Railway transportation is one of the most significant modes of continental transportation. The most relevant advantages of it - compared to road transportation - are the following [1]:

- The high travel/transportation performance (it can be more comfortable);

- The environment protection property (it causes less pollutant emission);

- The speed can reach $350 \mathrm{~km} / \mathrm{h}$ (or higher) in passenger transport and up to $200 \mathrm{~km} / \mathrm{h}$ (or higher) in freight transport. 
In fixed-rail transportation, it is essential to have a system of geometrical size limits for the fixed-rail track, i.e., to keep specific track geometry and rail geometry parameters within the prescribed and requested values. These parameters are essential due to the lack of maneuverability, high vehicle weights, high speeds, and severe consequences of accidents. The parameters primarily depend on the allowed speed on the track in each case. In addition, track monitoring [2] [3] and the geometrical deterioration [4] [5] of the tracks are significantly essential.

In the case of tramways and (ordinary public) railway tracks, the following are usually distinguished in terms of track geometry parameters:

1) Track gauge, it is generally characterized by deviation from the nominal track gauge in mm unit;

2) Alignment, it is usually distortion-free and filtered for wavelengths D1 (3$25 \mathrm{~m}$ ) or arc-height (chord height) data defined in the middle of a symmetrical $10.0 \mathrm{~m}$ long chord from baseline to peak or from peak to peak (value on a straight line 0 , in the case of a curve, the alignment parameter is a function of the change in curvature);

3) Longitudinal level, it is usually distortion-free and filtered for D1 (3-25 m) wavelengths or arc height (chord height) data determined at the intermediate point of a chord of $11.8 \mathrm{~m}(5.0+6.8 \mathrm{~m})$ in $\mathrm{mm}$ unit, 'from baseline to peak' or 'from peak to peak' in mm unit (its value is 0 in the section between vertical curves on a faultless railway track section; in the case of a vertical curve the value of longitudinal level is a function of the radius of vertical curvature);

4) Superelevation (cross-level): height difference between outer and inner rail in mm unit;

5) Plane distortion (twist), it is the difference in cross-level (cross-level deviation) for a given base length (1.5-2.5-6.0-8.0 m), its unit is $\mathrm{mm} / \mathrm{m}$; the value of twist depends on the superelevation transition;

6) Curvature, it is the reciprocal of the radius of curvature belonging to the instantaneous topographical (i.e., horizontal) tangent, its unit is $1 / \mathrm{m}$ or $1 / \mathrm{km}$;

7) Other, e.g., calculated parameters (change of track gauge, etc.).

The definition of the track gauge is the distance of two rails (interpreted between lines perpendicular to the rails' running surface) in a given track section. The value of $Z_{p}$ is generally $14 \mathrm{~mm}$ for flat-bottom rails (this is true for Vignol rail profiles; however, it is $9 \mathrm{~mm}$ for grooved (Phoenix) rails); the measurement principle is shown in Fig. 1. This $14 \mathrm{~mm}$ depth allows the measurement to be less affected by the rail head's lateral wear and the enclosure radius [6]. 


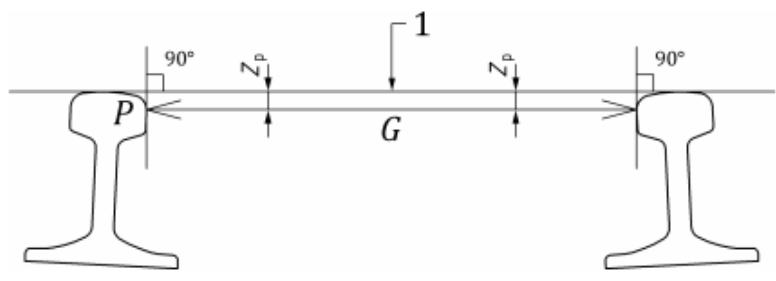

Figure 1

The measurement principle of track gauge [6]

Table 1 contains the various types of track gauge on world railways currently operated without claiming completeness.

Table 1

Various track gauges on world railways [7] (Remark: the $1520 \mathrm{~mm}$ track gauge is also a well-known and widely used value as the $1524 \mathrm{~mm}$ track gauge)

\begin{tabular}{|c|c|c|c|c|}
\hline $\begin{array}{l}\text { Type of track } \\
\text { gauges }\end{array}$ & $\begin{array}{l}\text { Size of } \\
\text { track } \\
\text { gauge } \\
{[\mathrm{mm}]}\end{array}$ & $\begin{array}{l}\text { Size of } \\
\text { track } \\
\text { gauge } \\
\text { [feet] }\end{array}$ & $\begin{array}{l}\% \text { of } \\
\text { total } \\
\text { length }\end{array}$ & Countries \\
\hline Standard gauge & 1435 & 4'8.5" & 62 & \multirow{6}{*}{$\begin{array}{l}\text { England, USA, Canada, Turkey, Persia and } \\
\text { China } \\
\text { India, Pakistan, Ceylon, Brazil, Argentina } \\
\text { Russia, Finland } \\
\text { Africa, Japan, Java, Australia, New Zealand } \\
\text { India, France, Switzerland, Argentina } \\
\text { various countries }\end{array}$} \\
\hline \multirow{4}{*}{$\begin{array}{l}\text { Broad gauge } \\
\text { Broad gauge } \\
\text { Cape gauge } \\
\text { Metre gauge }\end{array}$} & 1676 & 5'6" & 6 & \\
\hline & 1524 & $5 ’ 0 "$ & 9 & \\
\hline & 1067 & 3'6" & 8 & \\
\hline & 1000 & 3'3.5” & 9 & \\
\hline $\begin{array}{l}23 \quad \text { various } \\
\text { other gauges }\end{array}$ & $\begin{array}{l}\text { different } \\
\text { gauges }\end{array}$ & $\begin{array}{l}\text { different } \\
\text { gauges }\end{array}$ & 6 & \\
\hline
\end{tabular}

In the case of track gauges occurring in Hungary, it is worth mentioning the value of $760 \mathrm{~mm}$; railway line No. 7 (Children's Railway) and No. 39 (Balatonfenyves narrow gauge railway) in Hungary also have this track gauge value.

The following options are available for measuring the track gauge on railway tracks (taking into account the cases in Hungary):

- Hand-operated track gauge and superelevation measuring equipment

- Track measuring system for surveying railroad geometry

- Track geometry measuring cars and wagons: FMK-004 track geometry measuring car, and FMK-007 track measuring wagon

One of the basic requirements for ensuring accident-free traffic is to keep the factors describing the condition of the railway within the size limits (geometrical tolerances) prescribed for compliance with the standards and regulations.

The neglected track also has an economic issue; i.e., the worse the track state is, the higher the cost of traction energy, the higher the amount of operation, maintenance and rehabilitation, and renewal costs [8]. 
It is not evident whether the track gauge (as a track geometry) parameter is influenced by the traffic (i.e., the million gross-tons; MGT) and the allowed speed (categories). The aim of the authors is to examine this dependence and variation. They have chosen ten railway lines in Hungary (with the help of the MÁV PLC.) and analyzed the track gauge parameter considering the last ten years.

\section{Methods}

While selecting the railway lines for the analysis (investigation), the authors covered the possible widest range, even in terms of quality, their role, the permitted speed of the vehicles running on them, and the gross tonnage loaded (i.e., the MGT). The railway lines have different geometric and line designs; they have other constructions (structures) and rail types in the diverse terrain of Hungary.

The following lines (line numbers) were chosen (see Figs. 2-7):

- $11,13,145,146,147$

- $1,30,70,100,120$ (these are double-track lines, only the data of the right track were processed and analyzed)

(The numbering is based on the line numbering system applied in track maintenance according to the Network Business Rules of the Hungarian Railways.)

The inspection time interval was the between 2011-2020. In some analyses, the authors slighty modified this time range.

The track geometry measurements were performed with FMK-004 and FMK-007 track geometry recording cars/wagons, owned, and operated by MÁV Central Rail and Track Inspection Ltd. (MÁV KFV). Thus, the authors were able to work with the raw data sets recorded every $25 \mathrm{~cm}$.

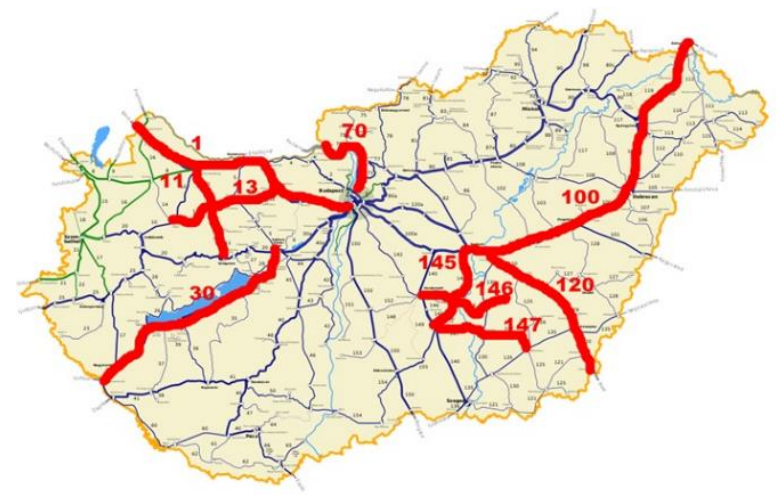

Figure 2

The investigated railway lines in Hungary 


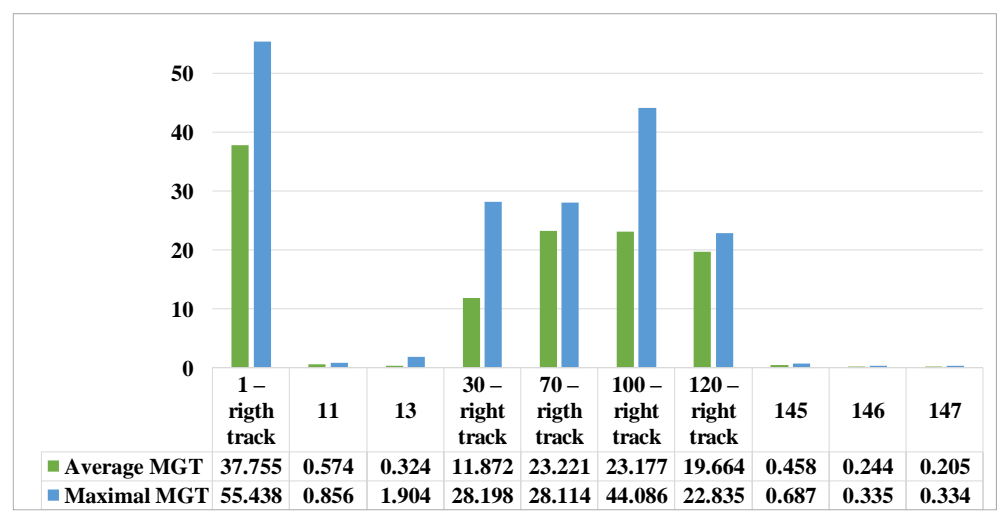

Figure 3

The average and maximal MGT values on the examined railway lines (between 2013 and 2019)

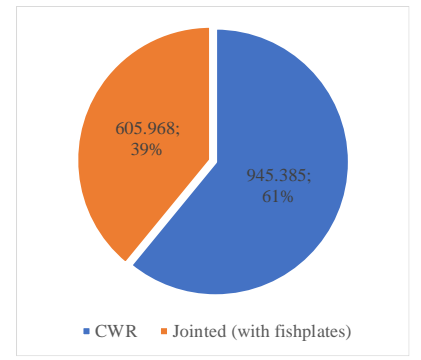

Figure 4

The ratio of the CWR tracks and the jointed tracks on the investigated railway lines (the numbers in the circle mean length values in kilometers)

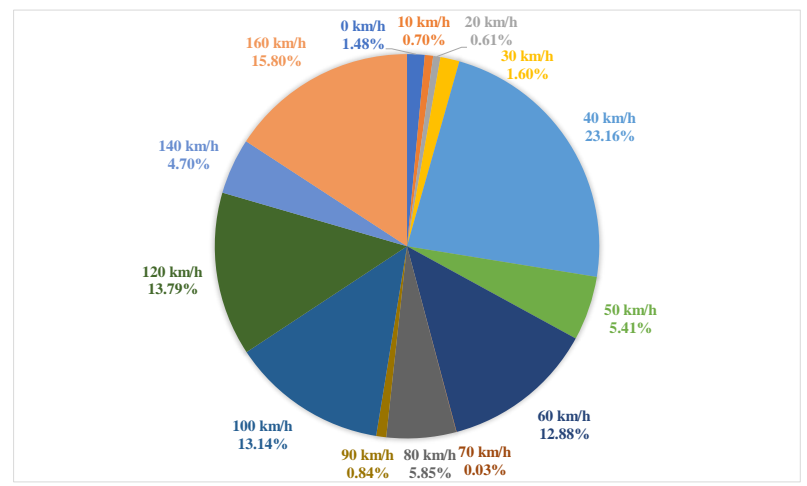

Figure 5

The ratio of the allowed speed values on the investigated railway lines 


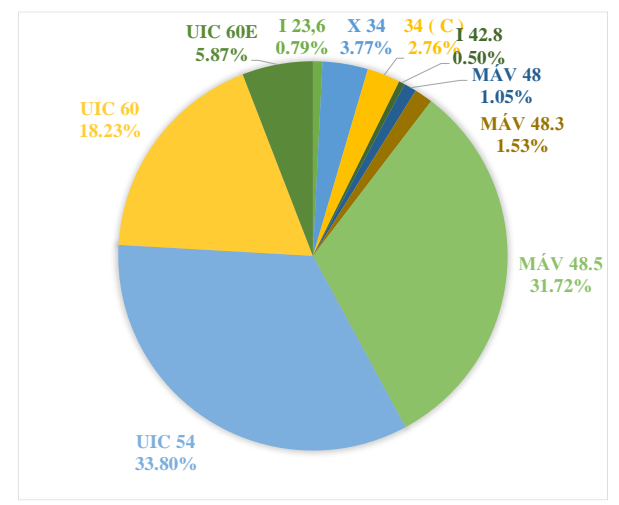

Figure 6

The ratio of the applied rail profiles on the investigated railway lines

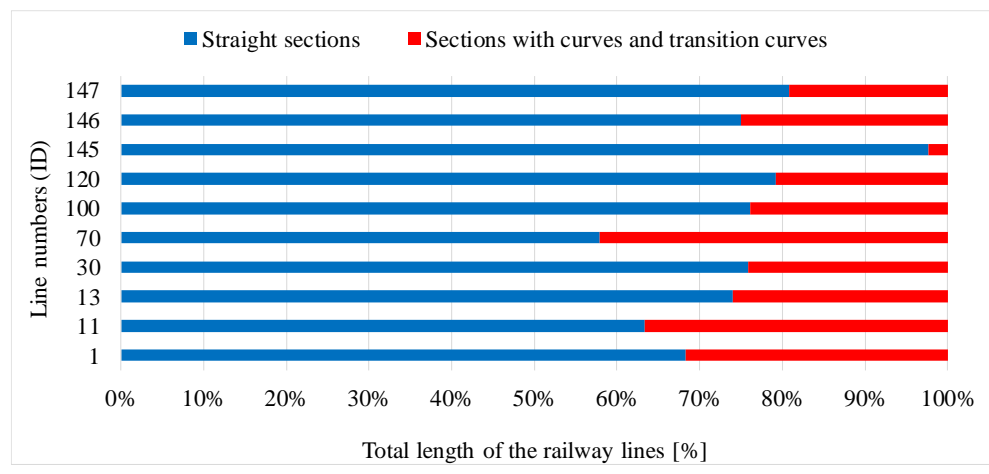

Figure 7

The ratio of the straights and curves sections on the investigated railway lines

In our research, we performed a large-sample statistical analysis.

The authors examined the rate of change of track gauge parameter as a function of time, its dependence on load and speed, the distribution of faults, and the descriptive statistical characteristics only on the straight sections of the railway lines.

To be able to easily plot and manage the 'change of the state or condition' described by the data, the Vaszary-type shape numbers were calculated for the distribution functions (curves) [9]. This shape number allows describing the condition of a track (or a whole railway line) characterized by big data set with a single number. The values for the quantiles of the distribution functions (i.e., $15 \%, 50 \%$, and $85 \%$ ) had to be determined. Based the measurements, the characteristics of the condition was calculated in Eq. (1).

$I_{\text {track gauge }}=\frac{\left(i_{15 \%}^{2}+i_{50 \%}^{2}+i_{85 \%}^{2}\right)}{10}$ 
The authors randomly selected 1-1 random data sets for each railway line for which they performed a statistical test. The authors examined whether the measurement data sets show a normal or lognormal distribution. To the lognormal distribution, $10 \mathrm{~mm}$ (in some cases $20 \mathrm{~mm}$ ) was added to the measured values so that their ebased logarithm ( $e=2.718)$ could be interpreted. It was only a transformation that did not modify the fundamental property of the statistical distribution. The calculations were executed with Kolmogorov-Smirnov statistical test in MS Excel software (chi-square, Shapiro-Wilk, Jarque-Barre, D’Agostino-Pearson tests would also have been possible). The authors also defined the skewness and peak characteristics for the distributions, which show how much and how the given distribution deviates from the normal distribution.

In the case of track geometry measurements, according to the TSI regulation [10], for the longitudinal level (i.e., settlement) and alignment parameters, it is compulsory to filter the measurement results so that only the part representing them in a specific wavelength range appears in the result. For example, filtering is often used for the wavelength range D1 (wavelength between 3 and $25 \mathrm{~m}$ ).

There is no such filtering requirement for track gauge measurements. Still, the question arises as to what typical wavelengths are included in the national track gauge measurements' data sets, as it is possible to deduce from them the causes and nature of track gauge differences. Therefore, Fourier transformation was performed on the arbitrarily selected signal sequences so that the share of each wavelength component in the examined sample becomes visible.

\section{Results and Discussion}

During the time series analysis, the authors applied one measurement per year for the railway lines, which preferably covers the most extensive length of the railway line and contains various data from summer and winter. However, it has happened that specific measurement zones have been left out of the data series, so there is a difference in the number of pieces per year, which can have a minimal effect on the output results. However, the number of measurement data is still the case that they represent hundreds of thousands, millions of items each year.

The figures calculated for the data series are first the time followed by the traffic load (MGT). The main question is whether any dependency can be detected from the data. Fig. 8 illustrates the change of the calculated $\mathrm{I}_{\text {track gauge }}$ as a function of a time related to each railway line. 


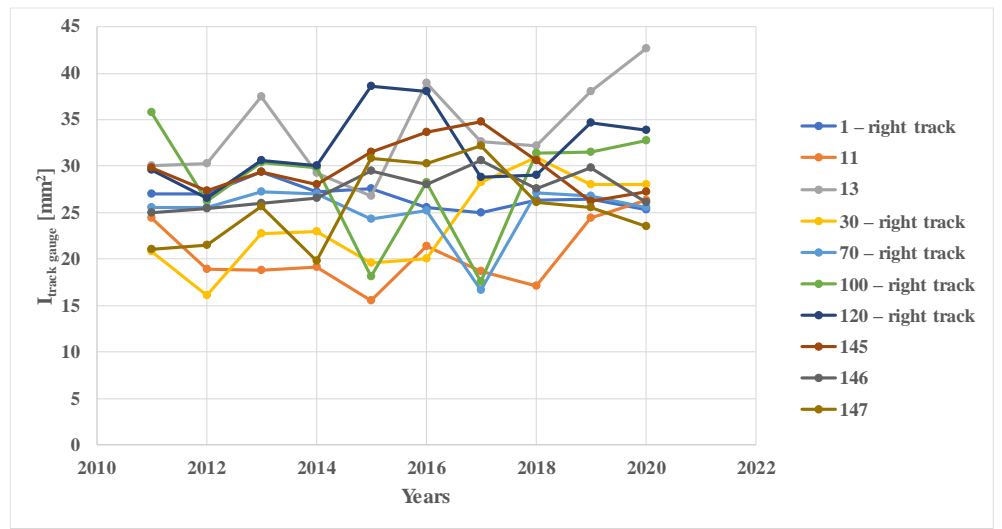

Figure 8

Change of the $\mathrm{I}_{\text {track gauge }}$ shape number as a function of the time

It can be seen in Fig. 8 that the charts (lines) approximately remain in the range of $15 \ldots 40 \mathrm{~mm}^{2}$. No significant trend can be observed for any of the railway lines. It is typically more alternating each data set in a given band. The larger the number of shapes, the flatter the defects distribution curve, i.e., the track gauge parameter moves over a broader range. Traffic load was also an aspect to be examined. However, the authors did not consider the above 'point graph' but a bar graph display expedient.

Fig. 9 illustrates the results, where the base railway line is railway line No. 1 (and its right track), while the authors chose 2019 as the base year. It can be stated that the result values depicted in Fig. 9 don't depend on traffic load (MGT), i.e., the track gauge parameter (and its change) does not rely on it either.

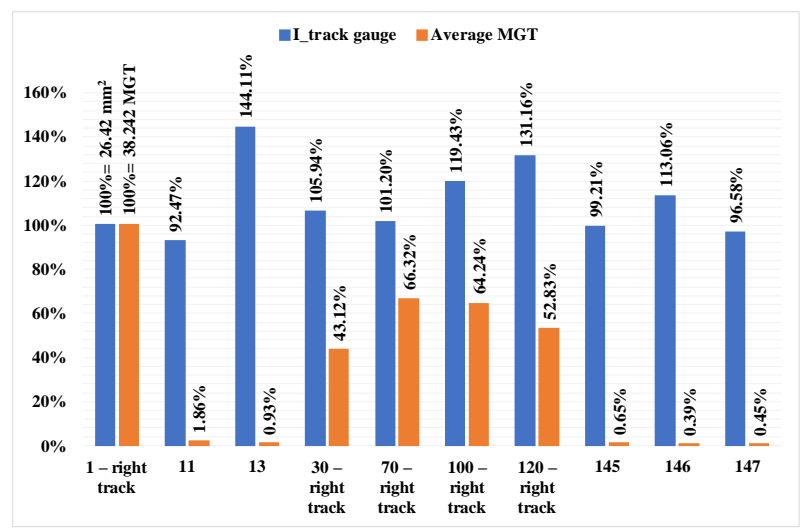

Figure 9

Change of the $\mathrm{I}_{\text {track gauge }}$ shape number as a function of the through-rolled axle tons (MGT); basis year is 2019 
Fig. 10 shows the change of the $I_{\text {track gauge }}$ shape number as a function of the time considering the allowed speeds.

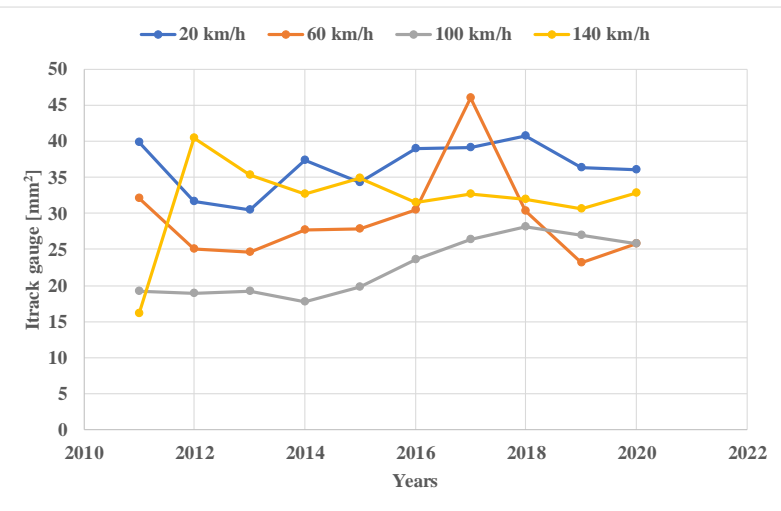

Figure 10

Change of the $\mathrm{I}_{\text {track gauge }}$ shape number as a function of the time considering the allowed speeds

Based on Fig. 10, in 2011, the expected order developed between the speeds, but it is characterized by volatility in the other years. The authors think the alternation can be the different speeds are a set of data from different types and qualities of tracks. In this way, the speed data set containing more data from subsidiary railway lines resulted in worse (higher) values than those related to only main railway lines.

Fig. 11 shows the mean and the standard deviation values in the whole inspected time range.

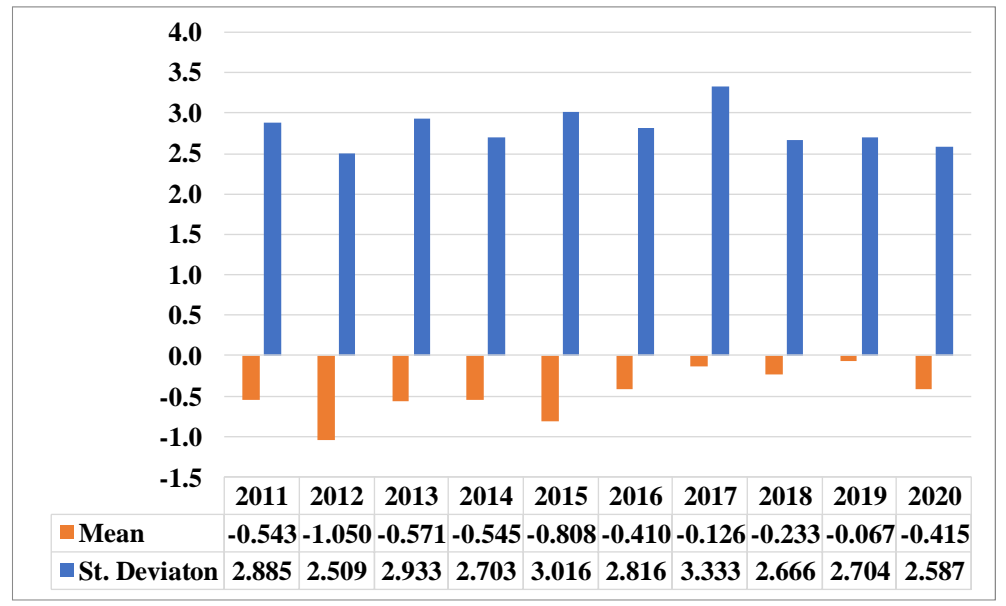

Figure 11

Change of the $\mathrm{I}_{\text {track gauge }}$ shape number as a function of the time considering the allowed speeds 
From the annual average values, it can be seen that Hungary is characterized by mainly track gauge narrowing (in the range of $0 \ldots-1.05 \mathrm{~mm}$ in the case of the examined railway lines).

The standard deviation of the examined straight track sections can be said to be uniform in the elapsed time; the difference between the maximum and minimum values is $0.824 \mathrm{~mm}$. The most significant rise occurred between 2016 and 2017, which means $0.517 \mathrm{~mm}$ in the current case, the most significant decrease between 2017 and 2018 is $-0.667 \mathrm{~mm}$.

Fig. 11 presents the results of the spectrum analysis related to the examined ten railway lines.

It can be seen that the extensions are located higher with several errors compared to the main lines (as expected). They contain a larger weight, a larger amplitude from a given wavelength.

The authors executed distribution analyses related to the data sets. Because of the limited space, there is no possibility to show the details; however, the results indicated that the received measurement data neither have Gaussian nor lognormal distribution. The analyses were related to Kolmogorov-Smirnov tests (i.e., the lognormal distributions were checked by the $\log (\mathrm{e})=\ln$ values of the original data sets).

The authors plan to continue their research in the future with considering only the curves and transition curves, analyzing the Fuzzy or Fuzzy-random behaviors of the measurements, etc.

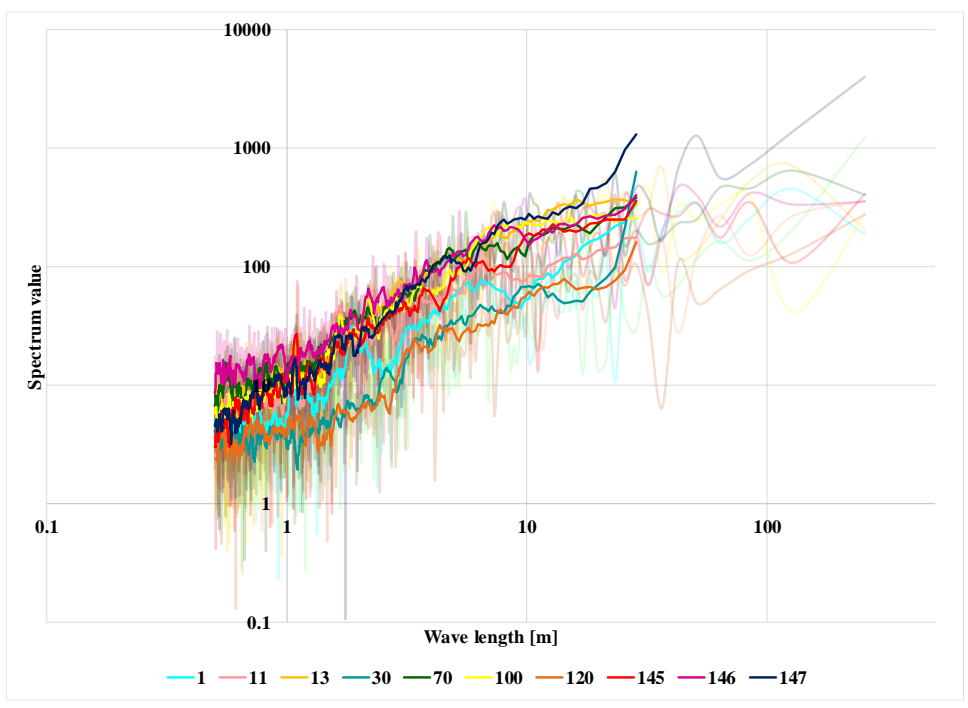

Figure 12

Result of the spectrum analysis 


\section{Conclusions}

The following conclusions can be drawn, based on the authors' research and results:

1) Considering the examined ten (10) railway lines, there is no significant correlation between the change of the track gauge, average and standard deviation values, elapsed time and traffic loading (i.e., MGT).

2) Typically, in Hungary, there is a narrowing of the track for the straight sections. As a result, the standard deviation of the errors is balanced.

3) The measured data sets of the 10 examined track gauge parameters have neither a Gaussian, nor a lognormal distribution.

4) The examined parameter is characterized by a peak and right-sloping shape distribution every year. Larger values in the sideline indicate that they deviate better from the normal distribution.

5) Lower velocities have a flatter distribution curve, steeper for higher speeds. Thus, it can be stated that the parameters deviated more from the nominal value at lower speeds.

6) In the case of the track gauge parameter, the distribution curves of the sidings were flatter, so the condition of the track is worse than expected.

7) The subsidiary contains a more considerable weight and amplitude from the given wavelength; they have more errors than expected.

\section{Acknowledgement}

The authors would like to express their thanks for the technical support of Hungarian Railways (MÁV) and MÁV Central Rail and Track Inspection Ltd. The primary helpers were A. Mátrai-Ortelli, D. Kovács-Balázs and C. Ágh.

\section{References}

[1] M Sysyn, V Kovalchuk, U Gerber, O Nabochenko, B Parneta, Laboratory evaluation of railway ballast consolidation by the non-destructive testing. Communications-Scientific letters of the University of Zilina, Vol. 21, No. 2, 2019, pp. 81-88

[2] A. Kampczyk, K. Dybel, The fundamental approach of the digital twin application in railway turnouts with innovative monitoring of weather conditions. Sensors, Vol. 21, No. 17, 2021, 5757

[3] A. Matejov, J. Šestáková, The Experiences with utilization of BIM in railway infrastructure in Slovak Republic and Czech Republic. Transportation Research Procedia, Vol. 55, 2021, pp. 1139-1146

[4] M. Sysyn, O. Nabochenko, V. Kovalchuk, M. Przybyłowicz, S. Fischer, Investigation of interlocking effect of crushed stone ballast during dynamic loading. Reports in Mechanical Engineering, Vol. 2, No. 1, 2021, pp. 65-76 
[5] A. Németh, S. Fischer, Investigation of glued insulated rail joints applied to CWR tracks. Facta Universitatis-Series Mechanical Engineering, 2021, 7642

[6] MSZ EN 13848-1:2004, Railway applications/Track. Track geometry quality. Part1: Characterisation of track geometry, $24 \mathrm{p}$.

[7] S. Chandra, M. M. Agarval, Railway Engineering, Oxford University Press, India, 2013, $676 \mathrm{p}$.

[8] D. Kurhan, M. Kurhan, M. Husak, Impact of the variable stiffness section on the conditions of track and rolling stock interaction. IOP Conference Series: Materials Science and Engineering, Vol. 985, No. 1, 2020, 012005

[9] D. Németh, H. Horváth, Statistical distribution and time variation of the track gauge parameter on the lines of the Hungarian railways, taking into account several low- and high-traffic railway lines, SIU, 2020, $55 \mathrm{p}$.

[10] TSI. https://eur-lex.europa.eu/legal-content/EN/TXT/PDF/?uri=CELEX: 32014R1299\&from=HU [online, last visited on: 2021.10.15] 